\title{
EXECUTIVE INFORMATION SYSTEM (EIS) KINERJA STUDI KASUS: CABIN BASE MAINTENANCE PT GMF AEROASIA TBK.
}

\author{
Sudaryono ${ }^{1}$, Harco Lesli ${ }^{2}$ \\ Universitas Banten Jaya ${ }^{1}$, Universitas Bina Nusantara ${ }^{2}$ \\ E-mail: $\underline{\text { dryono@gmail.com }}{ }^{1}$, harcolesli@raharja.info ${ }^{2}$
}

\begin{abstract}
ABSTRAK
Being a company with a high level of productivity is the goal of all companies. If a company or organization has high productivity, the company or organization can be called an advanced company. PT GMF AeroAsia is one that always tries to increase its productivity. PT GMF AeroAsia is a company engaged in aircraft maintenance or known as Maintenance Repair and Overhoul (MRO). PT GMF AeroAsia always tries to improve its performance through increased manhours productivity. If the productivity productivity increases every year, the company's revenue or revenue can increase as well, thus the company will progress and develop to be equal to the world's top ten (10) Maintenance and Overhoul (MRO) companies as the vision of PT GMF AeroAsia is to become a top ten MRO in the World. Therefore, the research will be carried out by analyzing the performance through manhours productivity in every maintenance project in the base maintenance, especially in cabin base maintenance. In this study, an executive information system (EIS) in the form of a dashboard for decision makers such as managers, general managers and vice presidents will be proposed. The aim is as a source of information to identify, control performance and can help and support as a source of information for leaders in deciding wise and strategic decisions on performance, especially the performance of cabin base maintenance units at PT GMF AeroAsia.
\end{abstract}

Keyword: Dashboard, Executive Information System (EIS), Manhours productivity, MRO, Performance.

\section{PENDAHULUAN}

Dalam perawatan pesawat udara terdapat istilah Turn Around Time (TAT) yaitu waktu yang ditargetkan dalam melakukan maintenance atau perawat pesawat baik pesawat itu sendiri maupun komponen atau part-part pesawat. Oleh karena itu berdasarkan hasil observasi, ditemukan informasi bahwa salah satu yang mempengaruhi cepat atau lambatnya Turn Around Time (TAT) tersebut adalah ManhoursProductivity setiap individu manpowerdan unit kerja di cabin sehingga 
informasi mengenai Productivity Manhours menjadi kebutuhan yang sangat primer. Leader, supervisor, manager serta para decisionmaker membutuhkan sistem informasi yang mendukung pengambilan keputusan atau dikenal dengan istilah Decision Support System (DSS) yang dapat membantu dalam menargetkan waktu atau jumlah Turn Around Time (TAT) yang dibutuhkan untuk menyelesaikan perawatan pesawat atau komponen, oleh karena itu akan dilakukan analisa pada kinerja dengan menganalisa manhours productivity untuk mengetahui tingkat produktivitas pada unit tersebut dan mengetahui masalah lalu berusaha mencari solusi atas masalah yang ada.

\section{RUMUSAN MASALAH}

Beberapa hal-hal yang menjadi permasalahan di unit cabin base maintenance untuk dipelajari lebih lanjut adalah sebagai berikut :

1. Laporan atau informasi apa saja yang menjadi kebutuhan pimpinan baik manager, general manager dan vice precident yang terkait dengan kinerja unit cabin maintenance ?

2. Bagaimana bentuk laporan atau informasi yang dibutuhkan untuk memonitor dan mengontrol kinerja dilapangan yang dapat membantu dalam pengambilan keputusan?

\section{METODOLOGI PENELITIAN}

Penelitian ini menggunakan penelitian kuantitatif dengan metode deskriptif, menurut Creswell (2008), penelitian kuantitatif adalah sebuah penelitian sosial berdasarkan pada pengujian sebuah teori yang terdiri dari variabel-variabel, diukur dengan angka dan dianalisa dengan prosedur statistik untuk menentukan apakah generalisasi teori tersebut benar.

Menurut Asep (2015) penelitian kuantitatif menekankan fenomena-fenomena objektif dan dikaji secara kuantitatif. Maksimalisasi objektifitas desain penelitian ini dilakukan dengan menggunakan angka-angka, pengolahan statistik, struktur dan 
percobaan terkontrol. Untuk penelitian dengan metode deskriptif adalah metode penelitian yang ditujukan untuk mengembangkan fenomena-fenomena yang ada, yang berlangsung pada saat ini atau saat yang lampau. Penelitian deskriptif bisa mendeskripsikan suatu keadaan saja, tetapi bisa juga mendeskripsikan keadaan dalam tahapan-tahapan perkembangannya.

Metode pengembangan sistem dilakukan pada tiga hal yaitu (1) Analisa, (2) Desain (3) Implementasi dan dapat digambarkan sebagai berikut :

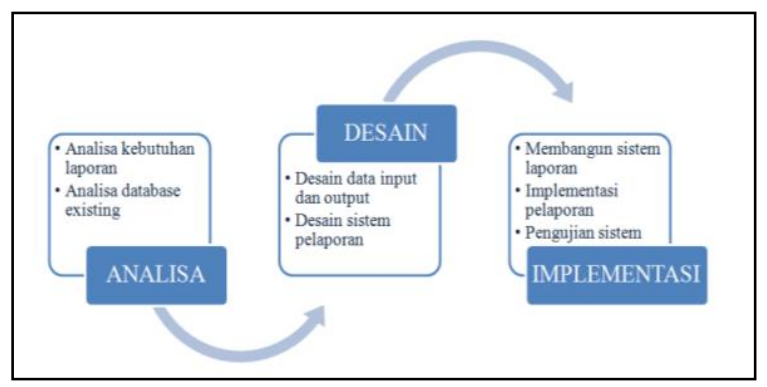

\section{Gambar 1. Desain Pengembangan Sistem}

Berdasarkan tiga pengembangan sistem di atas maka ada beberapa tahap kegiatan pada masing-masing bagian sebagai berikut :

\section{Analisa}

Pada tahap analisa yang perlu dilakukan adalah sebagai berikut :

1) Melakukan analisa terhadap kebutuhan informasi yang dibutuhkan oleh pimpinan

2) Melakukan analisa terhadap databaseMaintenace Project atau pekerjaan yang sedang dikerjakan

3) Melakukan analisa data dan informasi sistem yang berjalan berupa analisa terhadap prosedur, dokumen serta hasil cetakan dari sistem yang berjalan

4) Melakukan analisa terhadap kebutuhan fungsional seperti kebutuhan user yang harus terpenuhi dan kebutuhan nonfungsional atau kebutuhankebutuhan sistem yang tidak harus secara detail 
5) Melakukan analisa terhadap prilaku sistem dan dimodelkan dengan Actvity diagram yang bertujuan untuk memodelkan proses use case yang berjalan selain itu dapat pula dimodelka dengan sequence diagram yangbertujuan untuk memodelkan pengiriman pesan antar objek dan kronologi.

\section{Desain}

Pada tahap desain metode yang akan digunakan pendekatan adalah metode Object Oriented Design (OOD) atau perancangan berorientasi objek menggunakan Unifield Modeing Language (UML) dan tahapan kegiatan yang akan dilakukan adalah sebagai berikut :

a. Membuat atau mendesain user inteface meliputi form input seperti form manpower productivity, project report dan lain lain serta output berupa dashboard laporan progress pekerjaan

b. Membuat desain alur sistem pelaporan yang dapat dimodelkan dengan use case diagram

c. Untuk perancangan database dapat dimodelkan dengan menggunakan Entity Relatiaonship Diagram (ERD) dalam menghubungkan struktur datanya

d. Membuat rancangan terhadap infrastructure architecture seperti hardware, software dan jaringan

\section{Implementasi}

a. Menyediakan perangkat infrastruktur meliputi hardware, software dan jaringan

b. Membangun sistem dengan menggunakan bahasa pemrograman PHP dan database My SQL untuk database sistemnya

c. Mengimplementasikan proses penyajian laporan

d. Melakukan pengetesan dan pengujian terhadap sistem 
Jurnal Sistem Informasi dan Informatika (SIMIKA)

Vol.1 No.1 tahun 2018

\section{SISTEM YANG BERJALAN}

Untuk Pelaksaan pekerjaan dilapangan saat ini para Mechanic atau teknisisebagai eksekutor pekerjaan, mengambil jobcard atau MDR sebagai perintah pekerjaan di kantor Production planning and Controlling (PPC) kemudian melakukan barcoding untuk merecord hours atau manhours dari order yang sedang kerjakan setelah itu Jobcard tersebut dieksekusi oleh mechanic lalu kemudian dilakukan double check atau inspection oleh supervisor pada area-area yang membutuhkan safety yang tinggi, Setelah itu pada jobcard atau Maintenance Discrepancy and Rectification (MDR) tersebut diberikan stampMechanicpada komlom Mhecanic dan item-item yang diperlukan. Demikian pula dengan stamp Inspection dan signberikan pada kolom inspectionjika sudah dinyatak close atau selesai.

Untuk jobcard atau Maintenance Discrepancy and Rectification (MDR) yang sudah dinyatakan close, maka akan di input ke dalam sistem yang digunakan saat ini yaitu sistem SWIFT MRO untuk dilakukan updating pada seluruh order Jobcard dan MDR yang ada didalam sistem. Untuk pekerjaan yang statusnya progress dituliskan di handover maintenance bookagar dilanjutkan oleh manager shift berikutnya.

Pelaksaan atau distribusi jobcard yang dilaksanakan saat ini dapat ditampilkan dalam model usacase untuk mempermudah dalam memahami keseluruhan proses pekerjaan yang dilakukan dan berikut ini diagram usecase proses yang berjalan: 


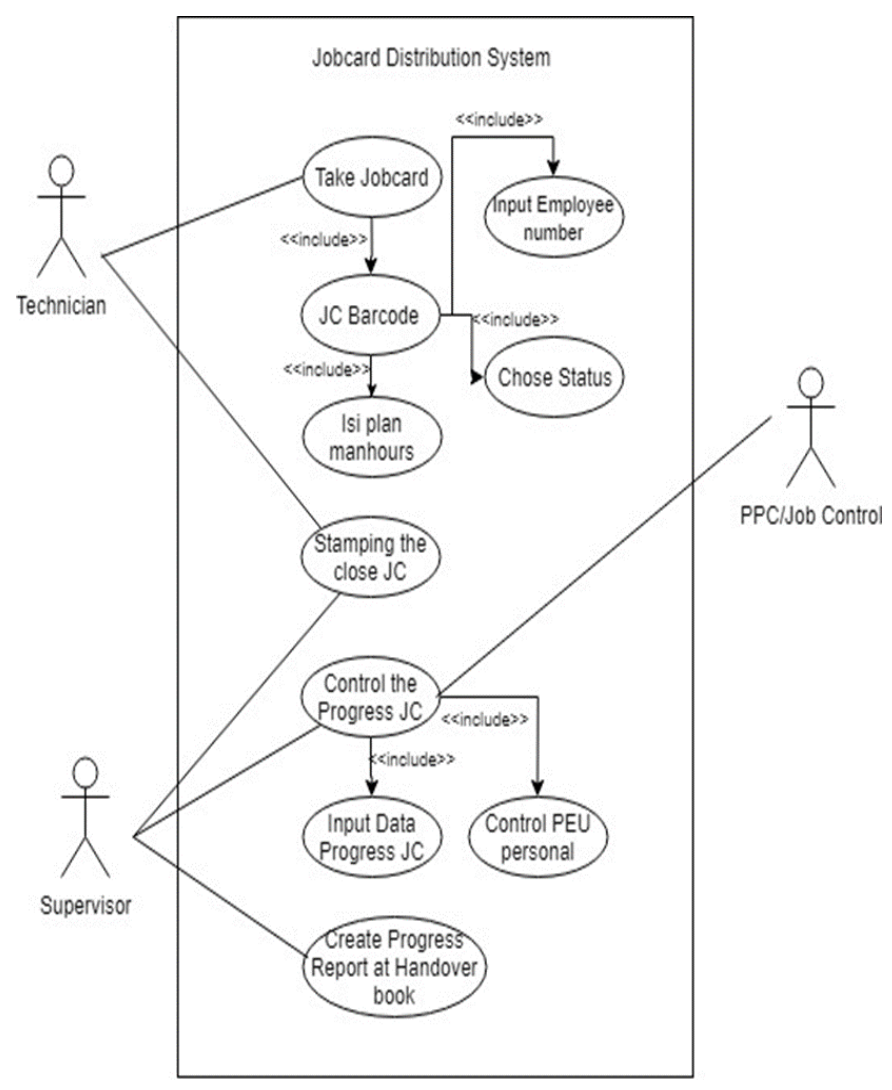

Gambar 2. Sistem yang berjalan

\section{DESAIN SISTEM}

Pada tahapan ini akan dipaparkan usulan solusi dari beberapa permasalahan yang sering terjadi dilapangan, seperti dijelaskandi awal bahwa delay turn around time (TAT) dalam proses maintenance merupakan salah satu masalah yang sering terjadi yaitu keluar dari jadwal yang ditargetkan. Turn Around Time ini merupakan target yang selalu dijadikan acuan atau pedoman berapa lama atau berapa hari pekerjaan sebuah proyek perwatan pesawat dapat diselesaikan.

Untuk mengahasilkaninformasi yang baik maka akan diusulkan beberapa solusi melalui desain-desain berikut ini :

1. Desain Input

Untuk mendesain bagian input dari sistem ini maka dibutuhkan data-data sebagai berukut : 
a. Data Perbaikan Pesawat

Data perbaikan pesawat adalah data keseluruhan pesawat yang sedang dalam proses maintenance khususnya yang ada di base maintenance dalam hal ini skope pekerjaannya meliputi pekerjaan cabin base maintenance

b. Data manpower atau personil

Data manpower adalah keseluruhan data-data pegawai yang akan di olah menjadi informasi yang dibutuhkan oleh pimpinan seperti (1) Data Manpower utilisasi atau penugasasan setiap pegawai pada pesawat apa mereka ditugasakan, tujuannya adalah untuk melakukan maping manpower sesuai dengan yang dibutuhkan oleh setiap proyek perawatan pesawat, (2)Jumlah keseluruhan pegawai baik pegawai tetap maupun pegawai kontrak berdasarkan unit-unit yangada di cabin base maintenance masing-masing. Tujuannya adalah untuk menjadi bahan informasi apakah perlu dilakukan rekruitmen terhadap pegawai tetap maupun pegawai kontrak berdasarkan kebutuhan yang ada. (3) Data mengenai jumlah pegawai yang memiliki stamp inspection (I) dan stamp mechanin $(M)$. Pegawai yang memiliki stamp Inpection adalah pegawai yang dapat dijadikan supervisor dalam bekerja sedangkan pegawai yang memiliki stamp mechanic adalah pegawai yang bisa ditunjuk sebagai leader dalam proses maintenace. Data tersebut nantinya akan dijadikan sumber informasi oleh pimpinan demi menetapkan perlunya upgrading pegawai atau tidak, jika para supervisor dirasa kurang maka pegawai yang memegang stamp mechanic (M) dapat diupgrade untuk mendapatkan stamp Inspection (I) sesuai dengan syarat-syarat yang berlaku, demikian pula dengan pemegang stamp Mechanic (M), jika dirasa kurang maka pegawai yang sudah layak dan memenuhi syarat memegang stamp Mechanic maka bisa dilakukan upgrading jika dirasa kurang.

c. Data laporan status pekerjaan

Data laporan status pekerjaan merupakan laporan kinerja cabinbase maintenance pada setiap proses maintenance yang dilakukan, jenisstatus untuk setiap laporan adalah (1) Open yaitu statu untuk setiap order atau 
jobcard yang belum dikerjakan, (2) Progress yaitu status untuk pekerjaan yang sudah dikerjakan namun belum selesai, (3) Close yaitu status untuk pekerjaan yang sudah dikerjakan dan dinyatakan selesai dengan melakukan stamping dan sign pada jobcard

\section{Desain Proses}

Alur atau proses dari sistem yang diusulkan disesuikan dengan jenis dan bentuk dari informasi yang dibutuhkan oleh para pimpinan. Tujuannya adalah agar pimpinan mudah memahaminya. Untuk proses atau alur dari sistem yang diusulkan dapat dilihat dari usecase berikut ini :

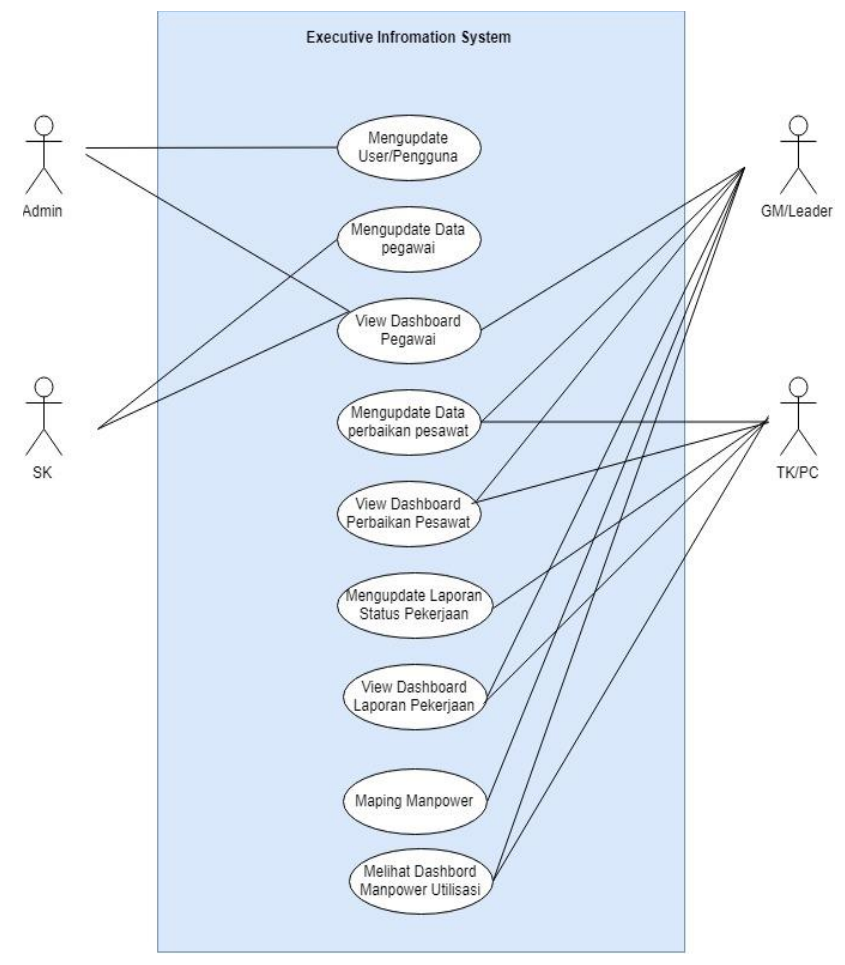

Gambar 1 Usecase Sistem yang diusulkan

\section{Desain Output}

Pada desain output ini akan diajukan usulan informasi yang disajikan dalam bentuk dashboard. Jika ada yang bertanya kenapa informasi yang disajikan untuk para pimpinan banyak menggunakan dashboard maka berikut ini jawabannya : (1) 
Dashboard adalah sebuah koleksi informasi yang bersifat realtime yang dapat digunakan untuk mengevaluasi performa atau kinerja dan memastikan bahwa tujuan dari operasional tercapai, Ronald (2010). (2) Dalam pengukuran pencapaian kinerja, dashboard secara harafiah, dashboard adalah panel kendali yang berada di depan pengemudi kendaraan bermotor, untuk mengendalikan informasi mengenai kondisi kendaraan bermotor, khususnya kecepatan, putaran mesin, suhu mesin, dan volume bahan bakar. Kinerja dapat diibaratkan sebagi dashboard bisnis bagi manajemen organisasi, yang menginformasikan keadaan atau status realisasi strategi organisasi, seperti pendapatan, profit margin, kepuasaan pelanggang dan sebagainya, dashboard bisnis yang efektif akan memberikan informasi yang jelas, konsisten, dan relevan mengenai kinerja organisasi sehingga memudahkan manajemen dalam melakukan analisa sebagai dasar pengambilan keputusan, Arini (2015). (3) Sebuah dashboard adalah sebuah informasi visual yang menyediakan informasi mengenai langkah-langkah penting yang relevan dengan tujuan tertentu atau proses bisnis, Alexander (2010).

Beberapa jenis informasi yang dibutuhkan pimpinan dalam membuat keputusan :

1. Dashboard Turn Araund Time (TAT)

2. Dashboard tentang manpower

a. Dashboard jumlah pegawai tetap dan kontrak

b. Dashboard pegwai dengan stamp Inspection dan Mechanic

c. Manpower utilisation atau schedule dan maping manpower

3. Dashboard kinerja cabin atau cabin performance report

\section{IMPLEMENTASI}

\section{A. Implementasi Sistem}

Jenis informasi yang dibutuhkan oleh pimpinan cabin base maintenancebaik manager, general manager dan vice precidentadalah (1)Informasi tentang turn around time (TAT) atau durasi lama waktu setiap proyek perawatan pesawat, (2)Jumlah manpower atau personil yang ada saat ini berdasarkan unitnya masing-masing, serta perbandingan manpower pegawai tetap 
Jurnal Sistem Informasi dan Informatika (SIMIKA)

Vol.1 No.1 tahun 2018

dengan pegawai kontrak, perbandingan jumlah pegawai yang memiliki stamp inspection (I) dengan jumlah pegawai yang memeliki stamp mechanic (M) serta (3)laporan progress pekerjaan baik jobcard maupun Maintenance Discrepancy and Rectification (MDR) yang statusnya open, progress dan close pada setiap proyek perawatan pesawat. Berikut ini tampilan dari dashboard-dashboard tersebut :

\section{Dashboard Turn Around Time (TAT)}

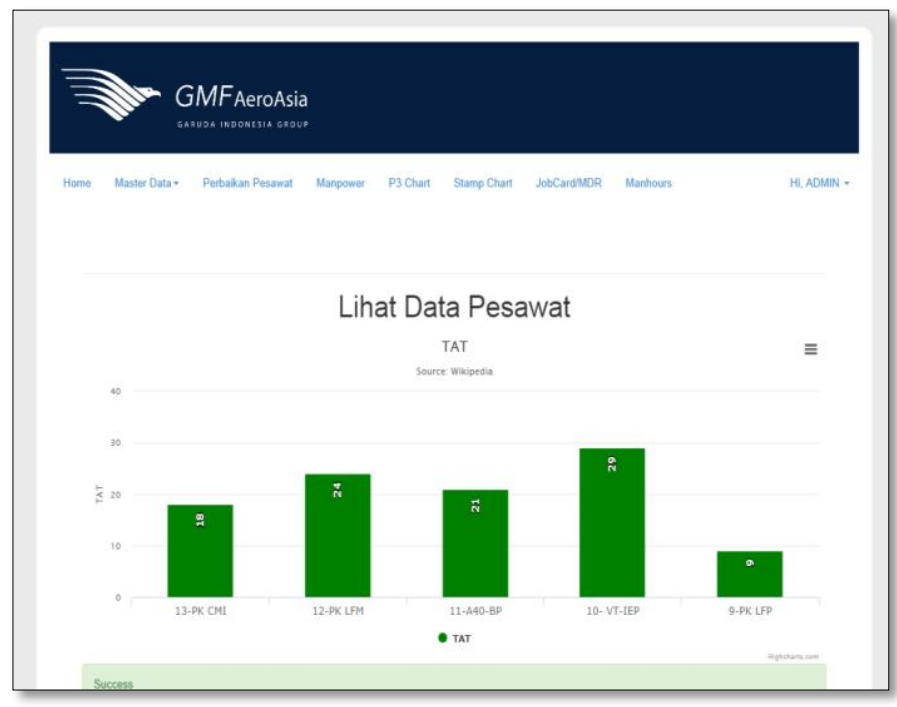

Gambar 2 Dashboard Turn Around Time

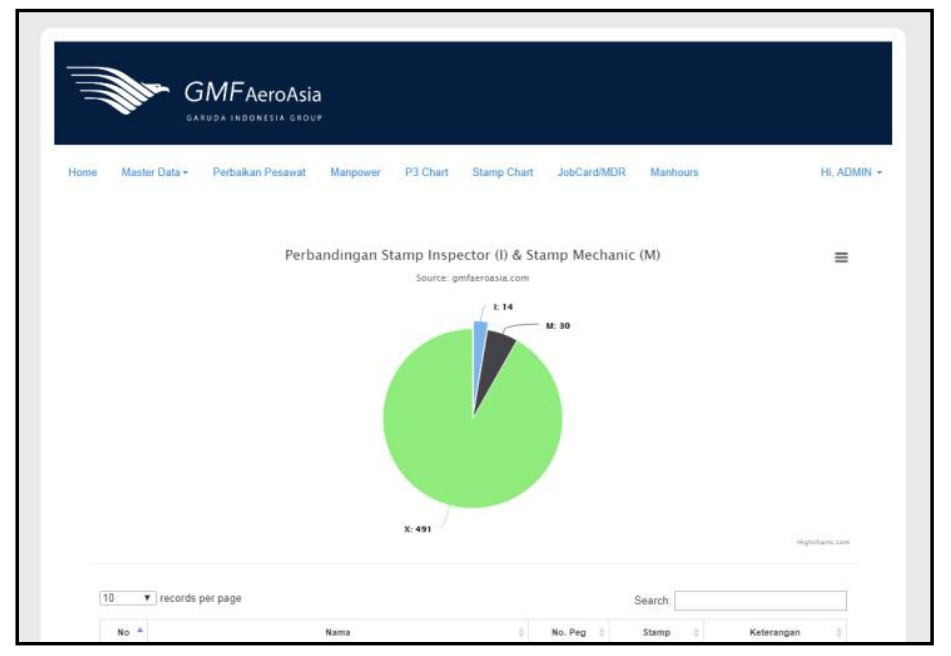

Gambar 3 Dashboard Pemegang Stamp I dan M 
Dashboard di atas menunjukkan informasi beberapa pesawat yang sedang dalam proses maintenance atau perawatan, jika dilihat dari grafiknya maka PK LFP menjadi pesawat dengan tingka prioritas yang lebih tinggi dibanding yang lainnya. Karena TAT-nya tersisa beberapa hari lagi dibanding yang lainnya, dengan demikian para pimpinan dapat terbantu untuk memutuskan agar pesawat tersebut diprioritaskan, dikerjakan dengan speed up dan diutilisasikan manpower yang cukup jika dirasa kurang.

\section{Dashboard Manpower}

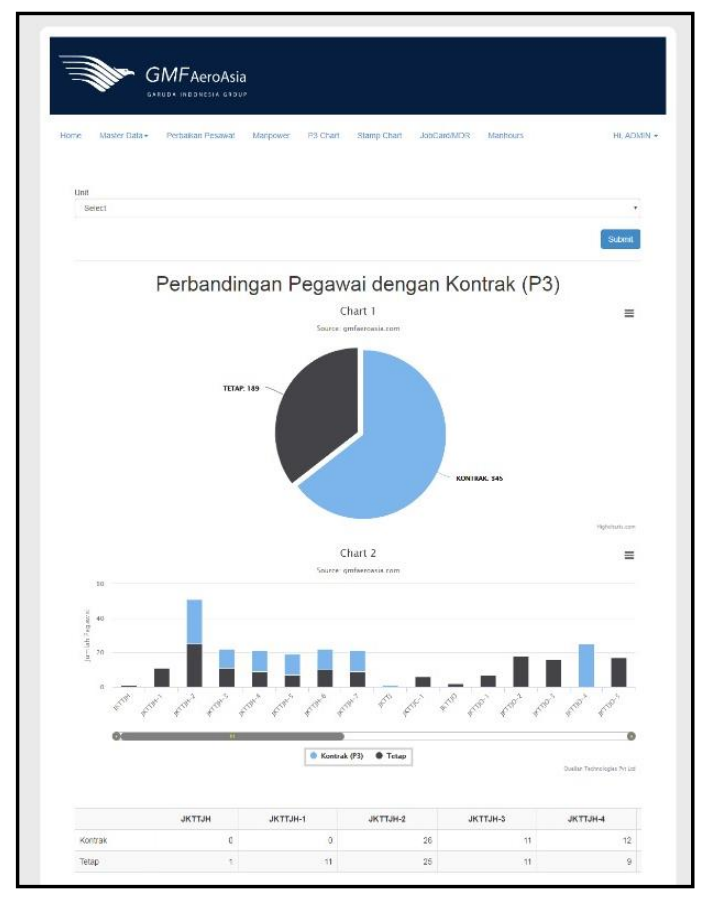

\section{Gambar 4 Dashboard Manpower Utilisasi}

Selain informasi mengenai TAT, Infomasi terkait manpower atau personil juga menjadi kebutuhan penting bagi pimpinan khususnya yang wilayah kerjanya di cabinbase maintenance. Manpower ini sebagai front line yang mengerjakan proses perawatan atau perbaikan pesawat, oleh karena itu dashboard informasi mengenai manpower dibagi dalam 3 bagian yaitu : 
1. Dashboard informasi mengenai jumlah manpower baik pegawai tetap maupun pegawai kontrak, tujuannya adalah untuk menjadi bahan informasi yang dapat membantu pimpinan dalam memutuskan penambahan jumlah pegawai jika diperlukan.

2. Dashboard informasi jumlah pegawai yang memilikistamp Inspection (I) danstamp mechanic (M).Pegawai yang sudah mempunyai stamp Inspection dapat diberikan tugas atau jabatan menjadisupervisor sedangkan pegawai yang mempunyaistamp Mechanic (M) dapat ditugaskan menjadileader dalam proses perawatan pesawat. Dengan adanya informasi ini para pimpinan dapat terbantu untuk memutuskan penambahan jumlah pegawai denganstamp inspectioan (I) ataustamp mechanic $(M)$ jika terjadi kekurangan berdasarkan kebutuhan dilapangan.

3. Dashboard informasi mengenai manpower untilisation yaitu informasi mengenai manpower yang ditugaskan bekerja di pesawat yang sedang dirawat. Informasi ini bertujuan untuk membantu pimpinan mengontrol, memonitor dan memilih manpower yang akan ditugaskan dipesawat $\mathrm{A}, \mathrm{B}$ dan $\mathrm{C}$.

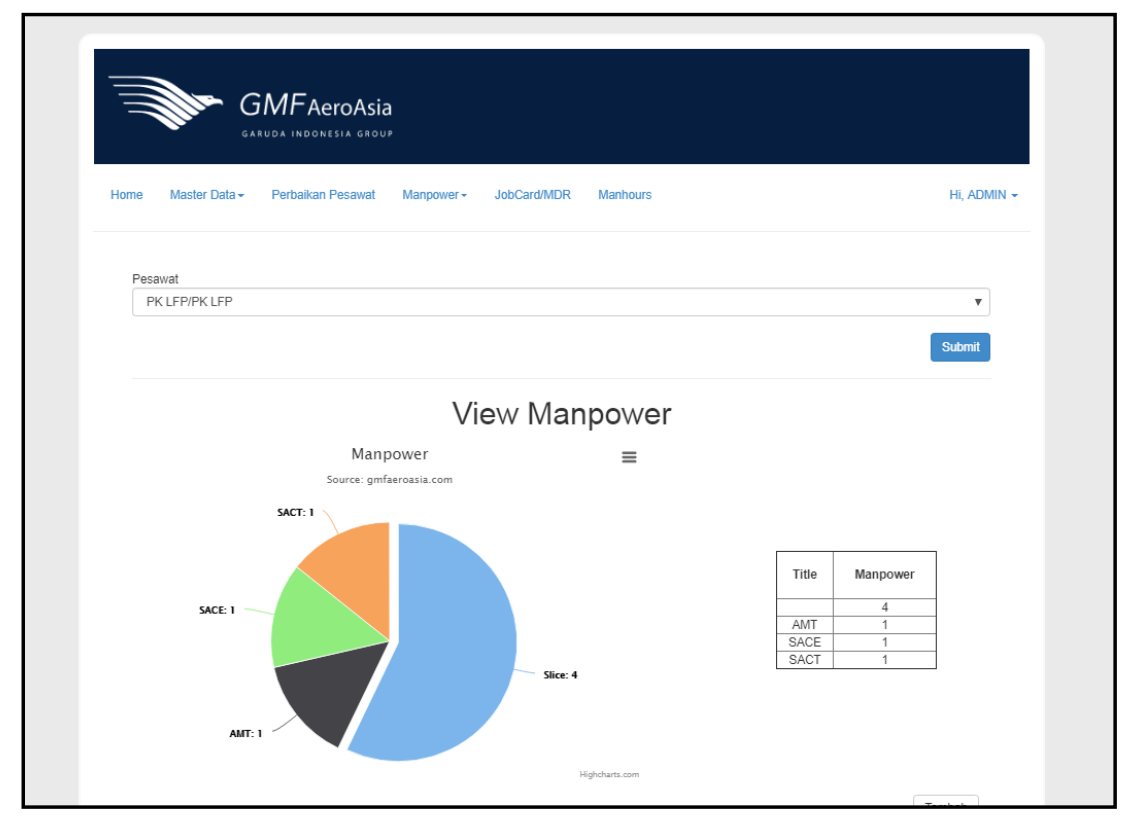

Gambar 5 Dashboard Jumlah Pegawai di unit Cabin 
3. Dashboard Kinerja atau Status Pekerjaan

Laporan pekerjaan yang ditampilkan dalam dashboard akan memudahkan para pimpinan dalam memonitor pekerjaan-pekerjaan yang ada di cabin base maintenance,tujuannya memberikan informasi mengenai status jobcard dan MDR yang statusnya Open yaitu pekerjaan yang belum dikerjakan, Progress yaitu pekerjaan yang sudah dikerjakan namun belum selesai dan Close yaitupekerjaan sudah selesai dan berikut ini tampilan dashboard-nya :

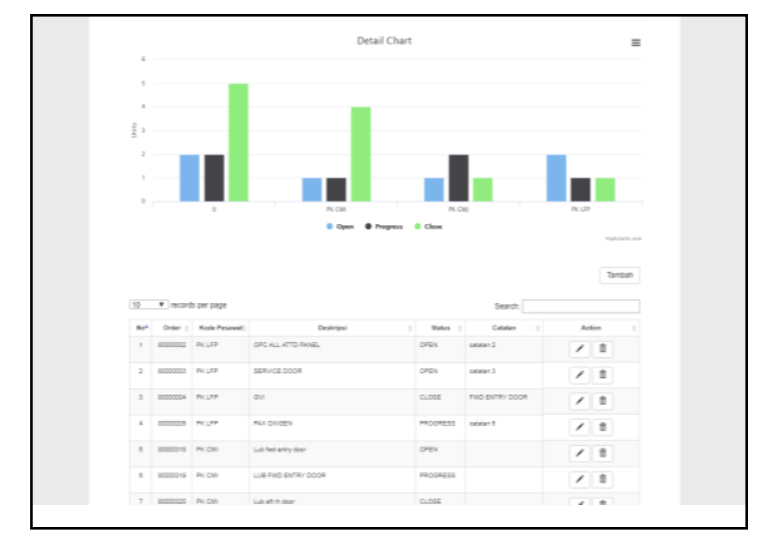

\section{Gambar 6 Dashboard Laporan Status Pekerjaan}

\section{Pengembangan Sistem}

Perbedaan dari sistem lama dengan sistem yang baru disusulkan ini adalah sistem yang lama memisahkan dashboard setiap proyek perawatan pesawat sehingga untuk mendapatakan informasi menganai dashboard perawatan atau perbaikan pesawat harus membuka sistem satu persatu sedangkan untuk sistem yang diusulkan ini para leader atau pimpinan cukup log in kedalam sistem dan dapat melihat semua projek yang sedang dikerjakan.

Selain menyatukan dashboard perbaikan pesawat, sistem yang diusulkan ini menyatukan informasi-informasi berupa dashbaoard yang berhubungan dengan pelaksanaan perawatan yaitu dashboard manpower atau para pekerja, penugasan pekerjaan atau manpower utilisasi dan informasi pegawai yang memiliki stamp. Demikian pula dengan informasi status pekerjaan yang ada pada proyek perawatan pesawa. Pada sistem yang sebelumnya semua informasi tersebut terpisah pada sistem 
yang berbeda dan sistem yang diusulkan berusaha menyatukan informasi-informasi yang dibutuhkan oleh para pimpinan proyek.

\section{KESIMPULAN}

Kesimpulan hasil laporan penelitian ini adalah melakukan perancangan dan mengembangan sistem yang dibutuhkan oleh para pimpinan, dengan tujuan sebagai sumber informasi untuk mengidentifikasi, mengontrol kinerja serta dapat membantu dan mendukung para pimpinan dalam memutuskan keputusan-keputusan yang bijak dan strategis terhadap kinerja, khususnya kinerja di unit cabin base maintenance PT GMF AeroAsia

Jenis informasi yang sudah dirancang dan dikembangkan sesuai kebutuhan para pimpinan unit cabin base maintenance adalah sebagai berikut :

a. Informasi mengenai Turn Around Time (TAT)

Dashboard Turd Around Time (TAT) atau lamanya waktu yang dibutuhkan untuk menyelesaikan setiap perawatan pesawat khusunya di cabin base maintenance, dashboard ini bertujuan sebagai alat bantu pimpinan dalam memonitor dan menontrol TAT setiap proyek perawatan pesawat dan menjadi acuan dalam memutuskan pesawat mana yang akan diprioritaskan berdasarkan dengan TAT masing-masing pesawat

b. Informasi mengenai manpower

1. Dashboard Manpower utilisasi yaitu penugasan manpower pada setiap proyek perawatan pesawat yang sedang dikerjakan. Tujuan dari dashboard ini adalah sebagai alat bantu pimpinan untuk memonitor jumlah manpower yang ditugaskan di pesawat yang sedang dikerjakan

2. Dashboard perbandingan antara pegawai tetap dan kontrak. Tujuannya adalah untuk menjadi bahan informasi bagi pimpinan jika pegawainya dirasa kurang maka dapat dilakukan penambahan pegawai baik pegawai kontrak maupun pegawai tetap 
3. Infirmasi mengenai pegawai yang memiliki stamp inspectiaon dan stamp mechanic. Dashboard ini bertujuan sebagai bahan informasi bagai pimpinan untuk menentukan supervisor dan leader dilapangan

c. Informasi mengenai laporan pekerjaan

Laporan pekerjaan dilaporkan berupa status setiap pekerjaan, untuk pekerjaan yang belum dikerjakan berstatus open, jika pekerjaannya sudah dikerjakan tetapi belum selesai maka jenis statusnya progress, sedangkan pekerjaan yang sudah dikerjakan dan sudah selesai maka status pekerjaan tersebut close

d. Informasi mengenai manhours

Informasi ini bertujuan untuk melihat jumlah manpower yang dibutuhkan untuk mengerjakan pekerjaan setiap jobcard atau MDR selain itu juga digunakan untuk melihat perbandingan plan manhours dari MPD dan plan mahours dari enginering yang disebut estimation manhour

\section{DAFTAR PUSTAKA}

Ahuya B.N., Dictinary of Management (Singapura: S.S. Mubarak \& Brothers Ltd., 1996), hlm.23

Astuti Yuli , (2011), Jurnal Dasi: Sistem Pendukung Keputusan Untuk Pemilihan Perguruan Tinggi Komputer Swasta, Vol. 12 :56-62

Malik Shadan, 2005, Enterprise Dashboard (Design and Best Practice for IT ), Canada, John Wiley \& Sons

Robbins Stephen P., Organization Behafiour: Concept,Controversies, and Applications, edisi ke 3 (Englewood Cliffs, New Jersey: Prentice-Hall, 1986), hlm.410.

Tariq Harry A,,2013,Aviation Maintenance Managemen, $2^{r d}$ ed., United States of America, Hill Company.

Tariq Harry A,,2008,Maintenance enginering Hand Book, $7^{r d}$ ed., United States of America, Mc-Graw Hill Companies.

Timajo Louie, (2014) 'Eropan Academic Research: Analysisof Aircraft Turn Around Time',Vol.II, Issue 7 : 9982-9993 